\title{
Particle Generation in Pulsed Plasmas
}

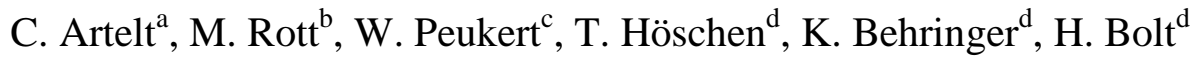 \\ ${ }^{a}$ Lafarge Research Centre, 38291 St. Quentin Fallavier, France \\ ${ }^{\mathrm{b}}$ Institute of Astronautics, Technische Universität München, 85747 Garching, Germany \\ ${ }^{c}$ Institute for Particle Technology, Friedrich-Alexander-Universität Erlangen-Nürnberg, 91058 Erlangen, Germany \\ ${ }^{\mathrm{d}}$ Max-Planck-Institute for Plasma-Physics, 85748 Gaching, Germany
}

\begin{abstract}
A new pulsed coaxial plasma generator (PCPG) has been developed in order to allow for investigating particle generation in the quench of a propagating jet. The related process provides an extremely transient environment which is characterised by initially high energy and charge densities, steep temperature gradients and short particle residence times. The combination of high quench rates and high charge densities, which can not be obtained in conventional reactors such as in flames or quasi stationary plasmas, provide in fact a potential for "freezing" of non-equilibrium phases and for tailoring particle characteristics by means of controlling particle-particle interactions. The pulsed plasma is characterised by means of determining the energy coupling, the charge density, the expansion behaviour, and the evolution of temperature. Particle properties such as primary particle size and aggregate structure are determined for varying process parameters, namely energy coupling, precursor injection, and ambient pressure.
\end{abstract}

Keywords: pulsed plasma generator, plasma quench, carbon black, particle charging, particleparticle interactions, emission spectroscopy

\section{Introduction}

Pulsed and therefore highly transient plasmas generally combine high energy $[1,2]$ and charge densities [3, 4], steep temperature gradients [5], and short residence times. Research in the field of such systems has so far mainly aimed at developing hypervelocity launchers $[6,7]$ and particle accelerators for micrometeoroid simulation $[8,9]$. Recent work furthermore deals with modifying surface layers, e.g. to improve corrosion [10] or wear resistance [11, 12]. However, particle formation and growth are inherent to pulsed plasma processes also, but have not yet been subject of intense investigations.

In fact, pulsed plasma arc discharges appear to provide a particular interesting environment for studying particle formation and growth: Due to the combination of high quench rates and high charge densities they have a potential to allow for "freezing" of non-equilibrium phases and for tailoring particle characteristics by means of controlling particle-particle interactions. Therefore, a new test unit has been designed, built and put into operation. It comprises a pulsed coaxial plasma generator which permits to study particle generation from the vapour phase at extremely transient process conditions. Carbon black was chosen as a model substance because of its great industrial relevance. It is - amongst other applications - used as a reinforcing agent in rubbers, in particular in tires, and as a pigment [13]. The PCPG applied within the frame of this work utilises gaseous precursors for particle generation, namely acetylene. This permits easy and precise precursor dosage without any need to consider additional equipment such as evaporators and heated ducts. 


\section{Experimental set-up}

A schematic of the test facility is depicted in fig. 1. It comprises a capacitor bank for energy storage, a gas injection unit, a plasma generator, and an expansion chamber with integrated instrumentation and diagnostics to determine plasma and particle characteristics. An initial static Ar-pressure between 0.4 and 100 mbar is established in the expansion chamber. The precursor gas $\left(\mathrm{C}_{2} \mathrm{H}_{2}\right)$ and an additional plasma gas (if required for spectroscopic purposes), are injected into the discharge chamber from pressurised reservoirs by rapid opening of the solenoid, i.e. magnetic valves. The gas injection is initiated by a trigger signal a few ms prior to the discharge of the capacitor bank. This ensures that an amount of gas large enough to generate the plasma between the electrodes arranged in a coaxial order flows into the discharge chamber in time. The required energy is provided by the capacitor bank with a capacity of $60 \mu \mathrm{F}$. At the maximum charging voltage of $14 \mathrm{kV}$, up to $5880 \mathrm{~J}$ can be supplied during a single discharge. The resulting surge current and the plasma discharge lead to the dissociation of the precursor and to almost full (single) ionisation of the gas mixture. Because of thermal expansion and interacting Lorenz forces the resulting plasma is accelerated from the discharge chamber into the large expansion chamber. The pressure release involved enforces rapid cooling and leads to particle formation and growth.

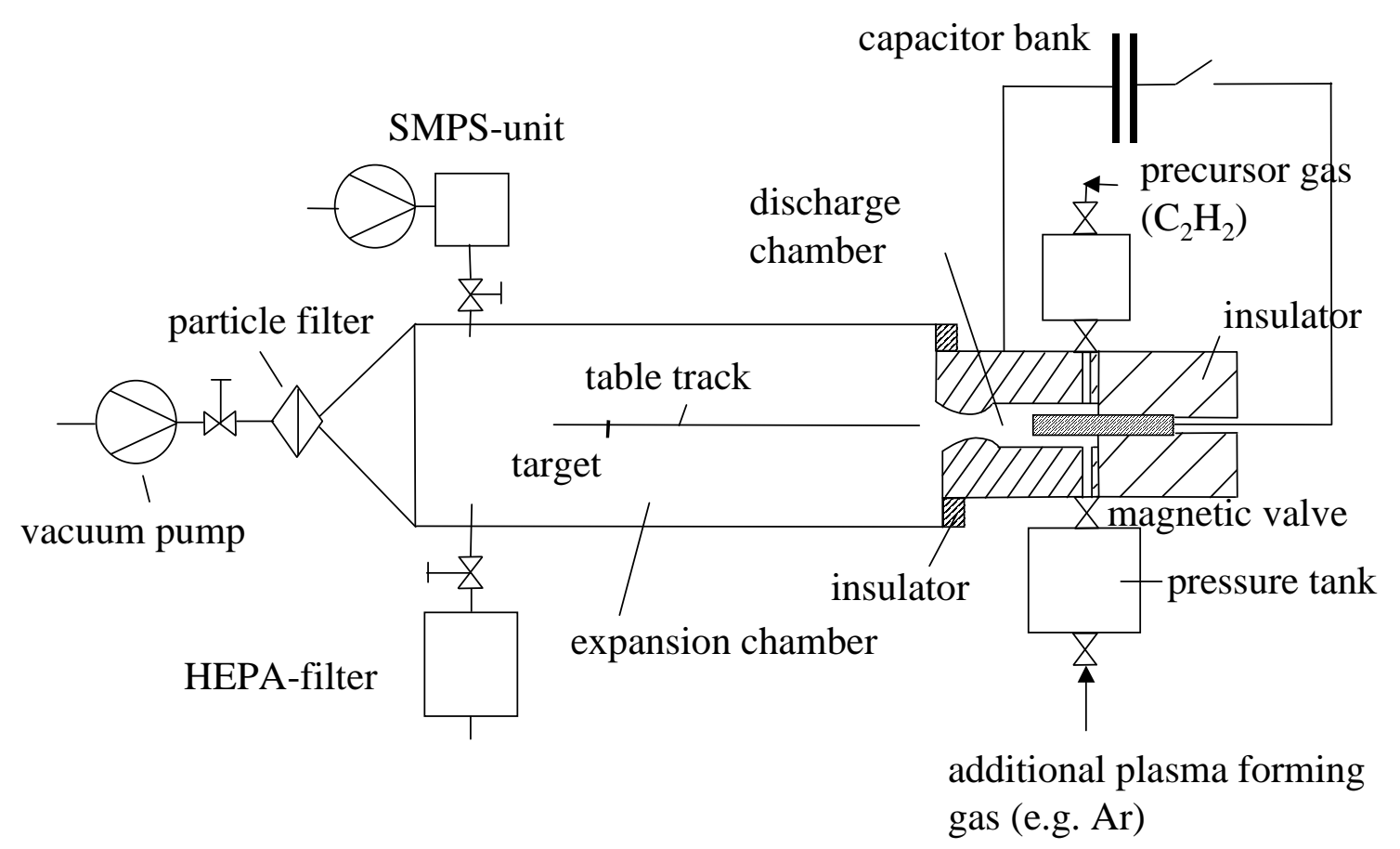

Fig. 1: Schematic of the test facility.

\subsection{Gas injection system}

A reliable injection system was designed and implemented in order to supply the process with defined amount of gas(es) just before the discharge is triggered. Solenoid valves which are directly mounted to the rear end of the discharge chamber serve to inject the gases. The opening velocity of these commercially available valves is significantly increased by means of activating the solenoids with a short over-current pulse. Minimum opening times of $2.5 \mathrm{~ms}$ can thus be realised. Since the solenoids face the high potential of the capacitor during discharge, their power supply has to be operated by high voltage relays. The filling of the pressure tanks with gas, its subsequent injection and the triggering of the capacitor are 
initiated by an automated sequencer. Delay times between the opening of the injection valves and the bank trigger are typically set to values between 4.5 and $10 \mathrm{~ms}$ in order to account for the time, which is required by the gas to flow out of the pressurised reservoir into the coaxial discharge chamber. The two gas lines (fig. 1) can be filled and injected individually with adjustable time delays.

\subsection{Plasma source}

The plasma source comprises a coaxial type electrode assembly which consists of an annular outer electrode and inner rod electrode. The electrodes are centred by an insulating structure which is made from polyethylenterephtalate, an oxygen rich hydrocarbon material. Both electrodes are made from brass and are connected to the capacitor bank and the ignitron switch with low inductive cables. A cross section of the plasma source which also includes a schematic of the energy supply is depicted in fig. 2. Its detailed description is given in [4]. The whole system, i.e. plasma source and electrical circuit components, is characterised by extremely rapid discharges with pulse durations ranging from some $10 \mu \mathrm{s}$ to some $100 \mu \mathrm{s}$. The length of the discharge pulse is mainly determined by the value of the variable inductance which is incorporated in the system. Further characteristic features are the very high surge current which is of the order of some $10 \mathrm{kA}$ and results in high electron and gas temperatures, and the high gas flow velocities, favoured by a Laval-type nozzle at the opening mouth of the discharge chamber. The coaxial geometry of the electrodes provides a large surface area for the arc discharge and therefore leads to rather low current densities. This design also minimises interfering ablation [4] and allows stable and highly reproducible self ignition.

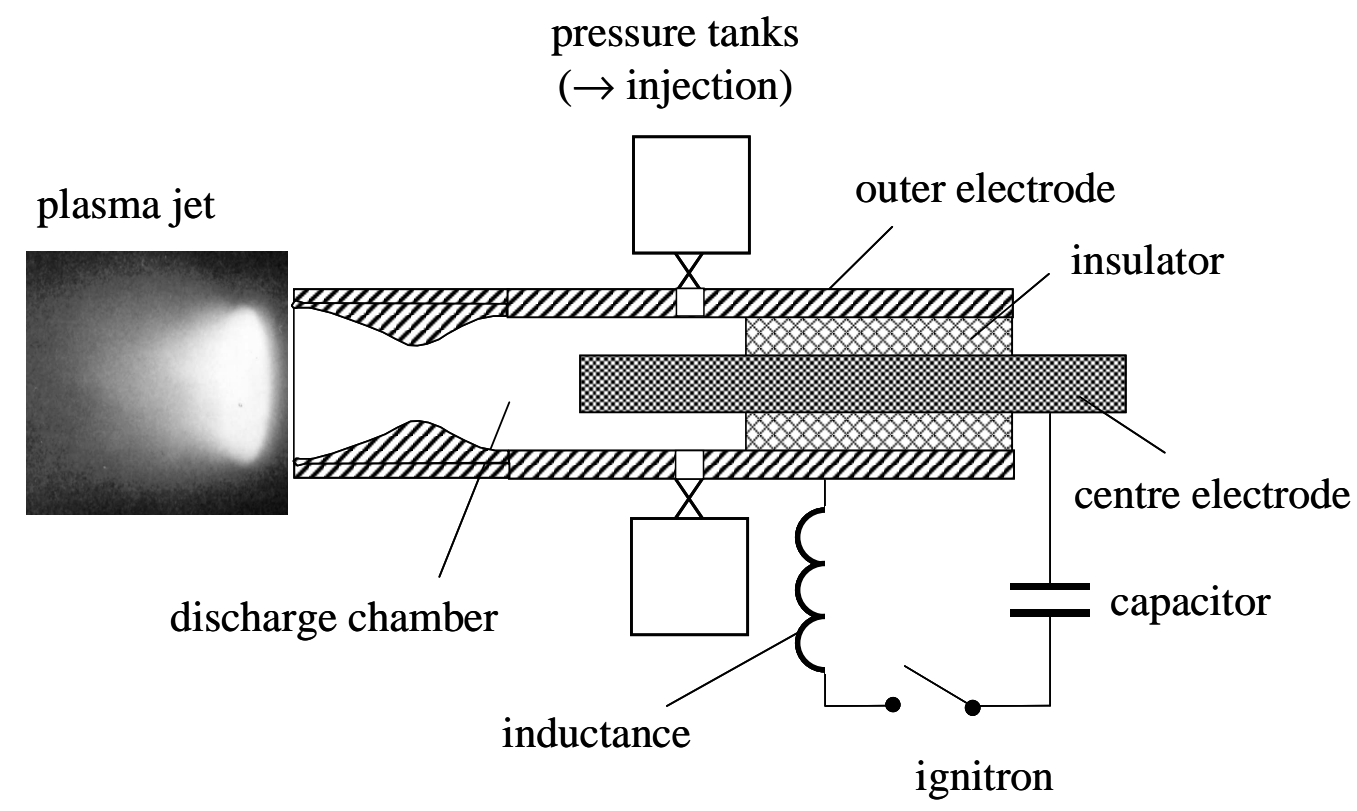

Fig. 2: Plasma source.

\section{Instrumentation}

Plasma and particle related measurement techniques applied within the frame of this study are summarised in fig. 3. These techniques permit to obtain a reasonably comprehensive picture of the whole process comprising plasma conditions, progression of the free flow in the expansion chamber and characteristics of the final product, i.e. the generated particles. 


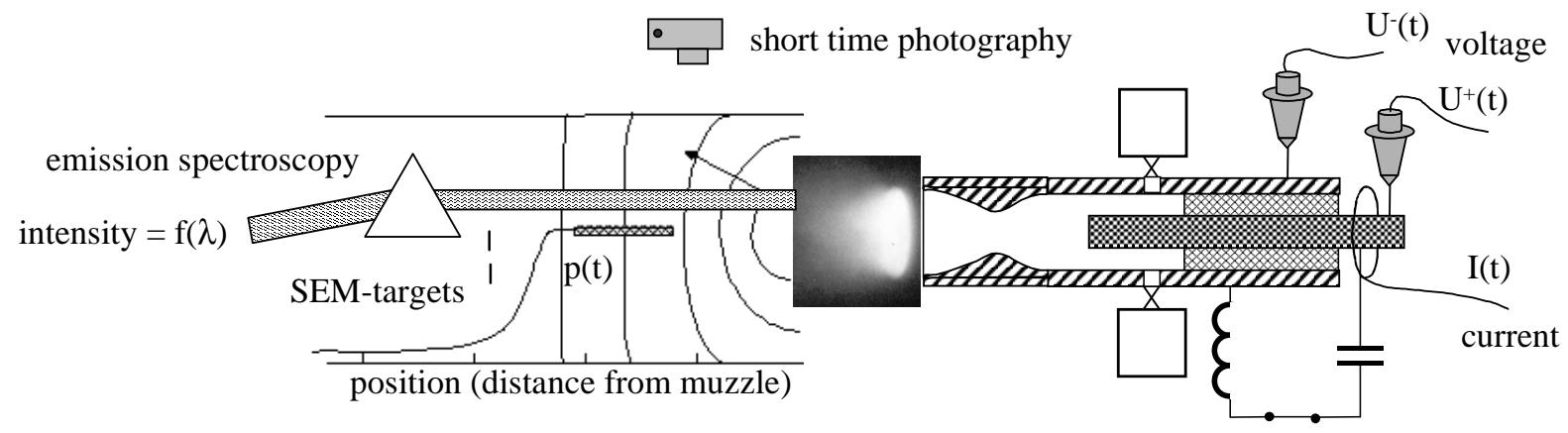

Fig. 3: Applied plasma and particle related measurement techniques.

\subsection{Plasma-related instrumentation}

Current and voltage probes are recorded in order to analyse the electrical behaviour of the plasma. A Rogowsky coil (PEM Ltd.) is used to measure the discharge current across the electrodes with reasonable accuracy. This coil actually records the propagation of the current $\mathrm{dI} / \mathrm{dt}$ during the arc discharge, but can be used to derive the current itself if comprising an integrating circuit. The progression of the voltage across the electrodes $U_{\text {diff }}$ (fig. 3 ) is measured with two Tectronix P6015 high voltage probes. To derive $U_{\text {plasma }}-$ i.e. the voltage drop of the plasma $-\mathrm{U}_{\text {diff }}$ has to be corrected by considering the inductive voltage drop in the coaxial electrode assembly ( $\rightarrow$ plasma source), i.e.

$\mathrm{U}_{\text {plasma }}=\mathrm{U}_{\text {diff }}-\mathrm{U}_{\text {plasma source }}$.

This correction $\left(\rightarrow U_{\text {plasma source }}\right)$ is a function of $\mathrm{dI} / \mathrm{dt}$ and of the inductance of the plasma source and is calculated according to

$$
\mathrm{U}_{\text {plasma source }}=\mathrm{L}_{\text {plasma source }} \cdot \frac{\mathrm{dI}}{\mathrm{dt}} \text {. }
$$

The inductance $\mathrm{L}_{\text {plasma source }}$ is approximately $95 \mathrm{nH}$ [4]. Since the resulting arc voltage $\mathrm{U}_{\text {plasma }}$ represents a purely ohmic voltage the ohmic resistance may be derived from dividing the voltage waveform through the current waveform. Waveform multiplication and integration leads to the time dependent energy coupling

$$
\mathrm{E}_{\text {plasma }}(\mathrm{t})=\int_{0}^{\mathrm{t}} \mathrm{U}_{\text {plasma }}(\mathrm{t}) \cdot \mathrm{I}(\mathrm{t}) \cdot \mathrm{dt}
$$

A Beckman \& Whitley camera is used for single frame short time photography in order to document plasma generation and expansion. The plasma jet is extremely luminous and permits to set exposure times to values as low as $10 \mu \mathrm{s}$. The limitation to single frame photography, however, requires taking several exposures at identical process conditions in order to obtain pseudo time resolved information.

A pressure sensor which can be fixed at a variable distance to the mouth of the plasma source is used to characterise the expansion behaviour of the plasma source. The piezo-type sensor has a very short response time of the order of $10 \mu \mathrm{s}$, which is little in comparison to the time scale of the axial propagation of the pressure front. However, the sensor is quite susceptible to 
the electromagnetic noise of the discharge and therefore has to be thoroughly shielded. The expansion velocity (profile) is obtained from delay times between capacitor discharge and sensor signal.

Emission spectroscopy is carried out during exemplary experiments in order to estimate the electron density, the electron, and the gas temperature. A grating spectrometer (CzernyTurner-Design, model Solar TII, Ms3504) with a maximum resolution $<0.1 \mathrm{~nm}$ is used. The spectra are recorded on a CCD camera chip (Sony ICX 285AL) with a minimum exposure time of $6 \mu \mathrm{s}$. However, as the time required by the chip to store the data is $500 \mu \mathrm{s}$, only one spectrum per experiment can be recorded, i.e. it is not possible to obtain time resolved information without repeating the experiment under identical process conditions. Stark broadening (see e.g. [14]) of the $\mathrm{H}_{\beta}$ line $(486.13 \mathrm{~nm}$ ) allows for estimating the electron density $n_{e}$ for each of the recorded spectra. The following relation can be used to derive $n_{e}$ :

$\Delta \lambda_{1 / 2}=\mathrm{C}_{4-2}\left(\mathrm{n}_{\mathrm{e}}, \mathrm{T}_{\mathrm{e}}\right) \cdot \mathrm{n}_{\mathrm{e}}^{2 / 3}$

According to Helbig and Nick [15], the constant $\mathrm{C}_{4-2}$ is about $2 \cdot 10^{-10}$ for the present conditions, if the full half-width $\Delta \lambda_{1 / 2}$ is given in $10^{-10} \mathrm{~m}$ and the electron density is measured in $\mathrm{cm}^{-3}$. In the present experiment, the $\mathrm{H}_{\beta}$ line width was roughly $3-6 \mathrm{~nm}$. The electron temperature in the arc channel is derived from the line ratios of argon and zinc atom and ion lines, i.e. ArII $415.6085 \mathrm{~nm}$ to ArI $415.8591 \mathrm{~nm}$ and $\mathrm{ZnII} 492.4013 \mathrm{~nm}$ to $\mathrm{ZnI} 481.0532 \mathrm{~nm}$. The plasma contains copper and zinc due to the inevitable electrode ablation, while argon is supplied as a tracer gas upon demand by making use of the second line of the gas injection system. The respective analysis is based on assuming local thermodynamic equilibrium (LTE) in the discharge chamber, i.e. that the excited ion states follow a Boltzmann distribution and that the atomic levels are in ionisation equilibrium with the ions. For the pertinent high electron densities (see below), this condition is well fulfilled. The gas temperature is not known and not relevant here, however, in the expanding free jet electron and gas temperatures are clearly different. Here, $T_{e}$ is measured by means of the intensity ratio of the two copper lines $\mathrm{CuI} 515.324 \mathrm{~nm}$ and $\mathrm{CuI} 510.554 \mathrm{~nm}$ [16]. The analysis is again based on a Boltzmann distribution in the neutral $\mathrm{Cu}$ I system, which is probably still a good assumption for the small energy differences of these levels. The gas temperature is derived from the rotational temperature of $\mathrm{C}_{2}$ molecular bands (Swan bands) according to Behringer [17] (fig. 9). The molecular constants needed are taken from Prasad and Bernath [18].

\subsection{Particle-related instrumentation}

Within the frame of this work, scanning electron microscopy (SEM) is carried out in order to characterise the generated particles in terms of their primary particle and aggregate size, their structure and the degree of sintering. The particles are collected on silicon wafers with a surface area of approximately $0.4 \mathrm{~cm}^{2}$. These wafers are placed in the centre of the propagation axis of the plasma jet and located in a distance of $20 \mathrm{~cm}$ to the opening mouth of the discharge chamber. The arc discharge, its subsequent propagation in the expansion chamber and the particle formation process involved are highly transient and take place in less than a ms. For such small residence times sintering on an initially cold target is of little importance [19]. Size and structure of the particles observed by means of the SEM do therefore well depict the state of the particles upon impacting on the Si-wafer. Of course, one has to keep in mind that some agglomeration on the target that may occur prior to securing it. In spite of this uncertainty, in-line measurement techniques such as scanning mobility particle sizing or in situ measurements such as time resolved laser-induced incandescence [20, 21] can 
not be applied here because of the highly transient character of the process and the subatmospheric pressure inherent to the system.

\section{Results and Discussion}

This section aims at characterising plasma and particle properties as a function of different process variables.

\subsection{Process variables}

The set of process variables under consideration comprises the pre-adjusted pressure in the expansion chamber, the amount of injected precursor gas, defined by the volume of the precursor tank and the pressure in there; the charging voltage of the capacitor, and the delay time between gas injection and arc discharge. With the exception of the delay time $\Delta t$, which is set to $10 \mu \mathrm{s}$ after an initial test focusing on characterising the gas flow into the discharge chamber - all parameters are varied as indicated in table 1 . Therein, the numbers printed in bold letters refer to the reference values as applied in the basic set of experiments. The maximum particle production rate for this first exploratory set-up is around $20 \mathrm{mg} / \mathrm{arc}$ discharge for a precursor tank pressure of 3.6 bars.

Table 1: Process variables.

\begin{tabular}{lc}
\hline Ar-pressure in the expansion chamber $\mathrm{p}_{\text {chamber,Ar }}$ & $0.4, \mathbf{1 0}, 100 \mathrm{mbar}$ \\
volume of the precursor tank $\mathrm{V}_{\mathrm{C} 2 \mathrm{H} 2}$ & $0, \mathbf{4 . 4} \mathrm{cm}^{3}$ \\
pressure in the precursor tank $\mathrm{p}_{\mathrm{C} 2 \mathrm{H} 2}$ & $0, \mathbf{1 . 1 5}, 2.5,3.6 \mathrm{bar}$ \\
charging voltage of the capacitor $\mathrm{U}_{\mathrm{C}}$ & $2.5, \mathbf{5 , 7}, \mathbf{9}, 12,14 \mathrm{kV}$ \\
\hline
\end{tabular}

Particle formation and growth do of course also depend on the characteristics of the test stand, i.e. on the geometry of the plasma source or on the electrical values of the discharge circuit. These parameters were, however, defined within preliminary tests [4] and are not varied here.

\subsection{Plasma properties}

Purpose of this section is to determine basic correlations between process variables - i.e. preadjusted pressure in the expansion chamber, amount of injected precursor and charging voltage of the capacitor bank - and the resulting plasma properties, namely temperature, electron density, and expansion velocity. The energy coupling $\mathrm{E}_{\text {plasma }}(\mathrm{t})$ into the plasma is a decisive link between process parameters and plasma properties and is therefore investigated first.

\subsubsection{Energy coupling}

The electrical energy $E_{\text {plasma }}(t)$ transferred to the plasma is determined by the progression of the discharge current $I(t)$ and of the arc voltage $U_{\text {plasma }}(t)$ (eq. 3), which is depicted in fig. $4 \mathrm{a}$ and $4 \mathrm{~b}$, respectively. All half-waves of the oscillating discharge amount to $62 \mu$ s regardless of the charging voltage of the capacitor bank. The current is a strong function of the charging voltage: Its amplitude is in fact proportional to $\mathrm{U}_{\mathrm{C}}$. During the first half-wave it amounts to $15.6 \mathrm{kA}$ for $\mathrm{U}_{\mathrm{C}}=5 \mathrm{kV}$ and to $41.0 \mathrm{kA}$ for $\mathrm{U}_{\mathrm{C}}=14 \mathrm{kV}$. The corresponding increase of the arc voltage is however little and only visible during the first few half-waves. The high voltage levels suddenly attained after some hundred $\mu$ s are due to the opening of the ignitron switch 
and refer to the remaining voltage on the capacitor. The corresponding energy of the capacitor then amounts to values between 1 and $5 \mathrm{~J}$ and can thus be neglected. The progression of the energy coupling into the plasma (eq. 3) is depicted in fig. 4c. $E_{\text {plasma }}$ continuously increases along $U_{C}$. However, the transfer efficiency $\eta$ defined as the ratio of the energy coupling to the energy initially stored on the capacitor bank decreases as $U_{C}$ increases (i.e. from 0.293 at $U_{C}$ $=2.5 \mathrm{kV}$ to 0.092 at $\mathrm{U}_{\mathrm{C}}=14 \mathrm{kV}$ ). This is due to the rapidly growing importance of the resistance in the electrical feed line.

Other process parameters, namely the $\mathrm{C}_{2} \mathrm{H}_{2}$ injection pressure $\left(\rightarrow \mathrm{p}_{\mathrm{C} 2 \mathrm{H} 2}\right)$ and the Ar-pressure in the expansion chamber $\left(\rightarrow p_{\text {chamber,Ar }}\right)$ only have a minor impact on the energy coupling. Increasing these pressures results in elevated concentrations of the species moving along the discharge chamber and consequently leads to a higher collision frequency for atoms, molecules, and charges, so that the transport of the latter ones is hindered to some extend. The level of the plasma resistance and of the energy coupling is therefore slightly increased.

\subsubsection{Expansion behaviour}

The expansion of the plasma is first characterised in terms of the progression of the pressure front. This front is derived from the signal of an extremely quickly responding pressure sensor (piezo type) placed at various distances from the opening of the discharge chamber. The resulting propagation velocity $c_{\text {prop }}$ is shown in fig. 5 for different charging voltages of the capacitor bank, (ambient) pressures in the expansion chamber, and gas injection pressures. $\mathrm{c}_{\text {prop }}$ strongly depends on these parameters and is of the order of 1000 to $2000 \mathrm{~m} / \mathrm{s}$ at a distance of $2 \mathrm{~cm}$ in front of the opening mouth of the discharge chamber. The propagation of the pressure front is favoured by high charging voltages and gas injection pressures and by low pressures in the expansion chamber: High capacitor voltages increase the discharge current and consequently lead to an enhanced electromagnetic acceleration along the coaxial electrode assembly due to Lorenz forces. The resulting current also enhances the energy coupling (fig. 4c) and is responsible for higher temperatures and pressures within the discharge chamber, which again accelerate the plasma propagation. The ambient pressure in the expansion chamber largely determines the rate at which the plasma jet is slowed down. The level of deceleration is high at the beginning of the expansion and particularly pronounced in the case of elevated ambient pressures. 

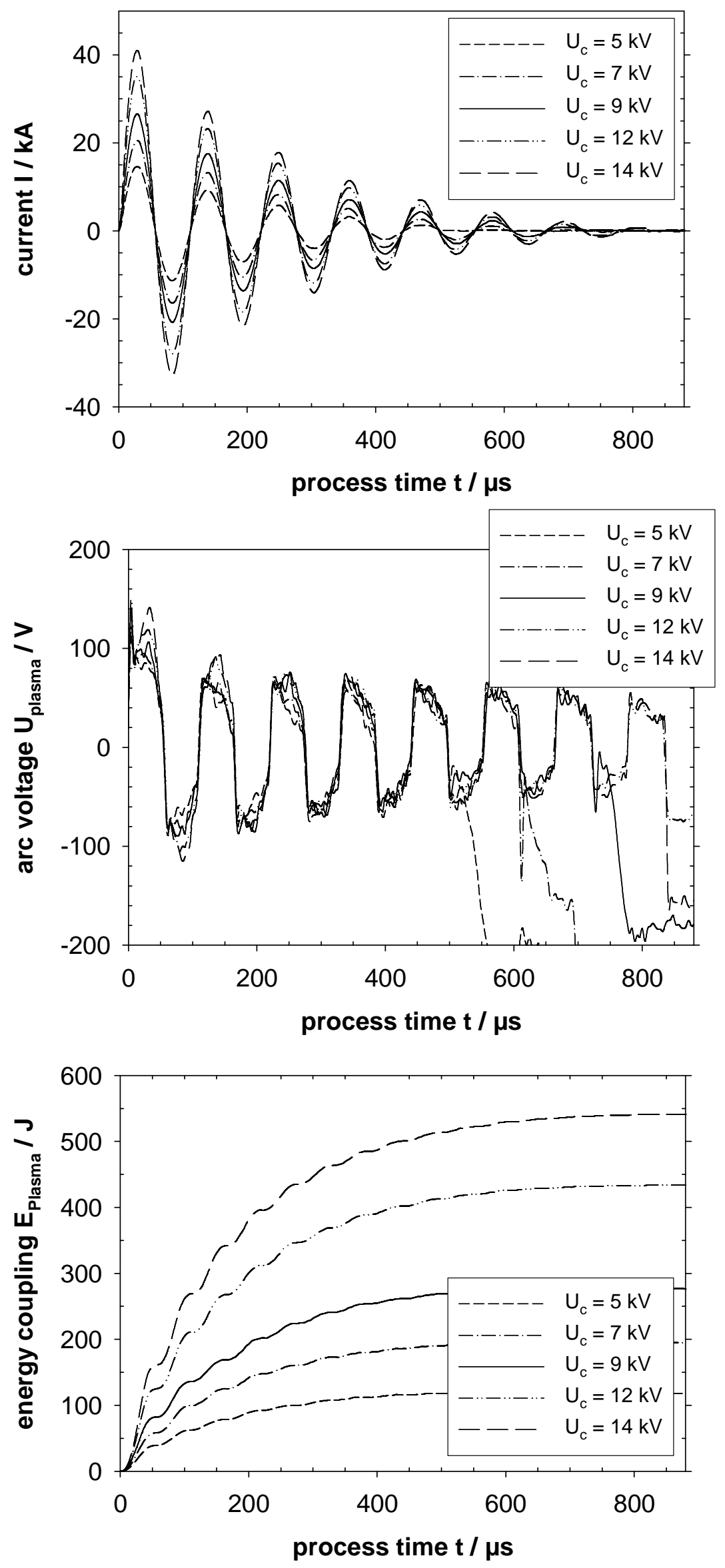

Fig. 4: Progression of a) current $\mathrm{I}(\mathrm{t}), \mathrm{b})$ arc voltage $\mathrm{U}_{\text {plasma }}(\mathrm{t})$, and $\mathrm{c}$ ) energy coupling $\mathrm{E}_{\text {plasma }}(\mathrm{t})$. 


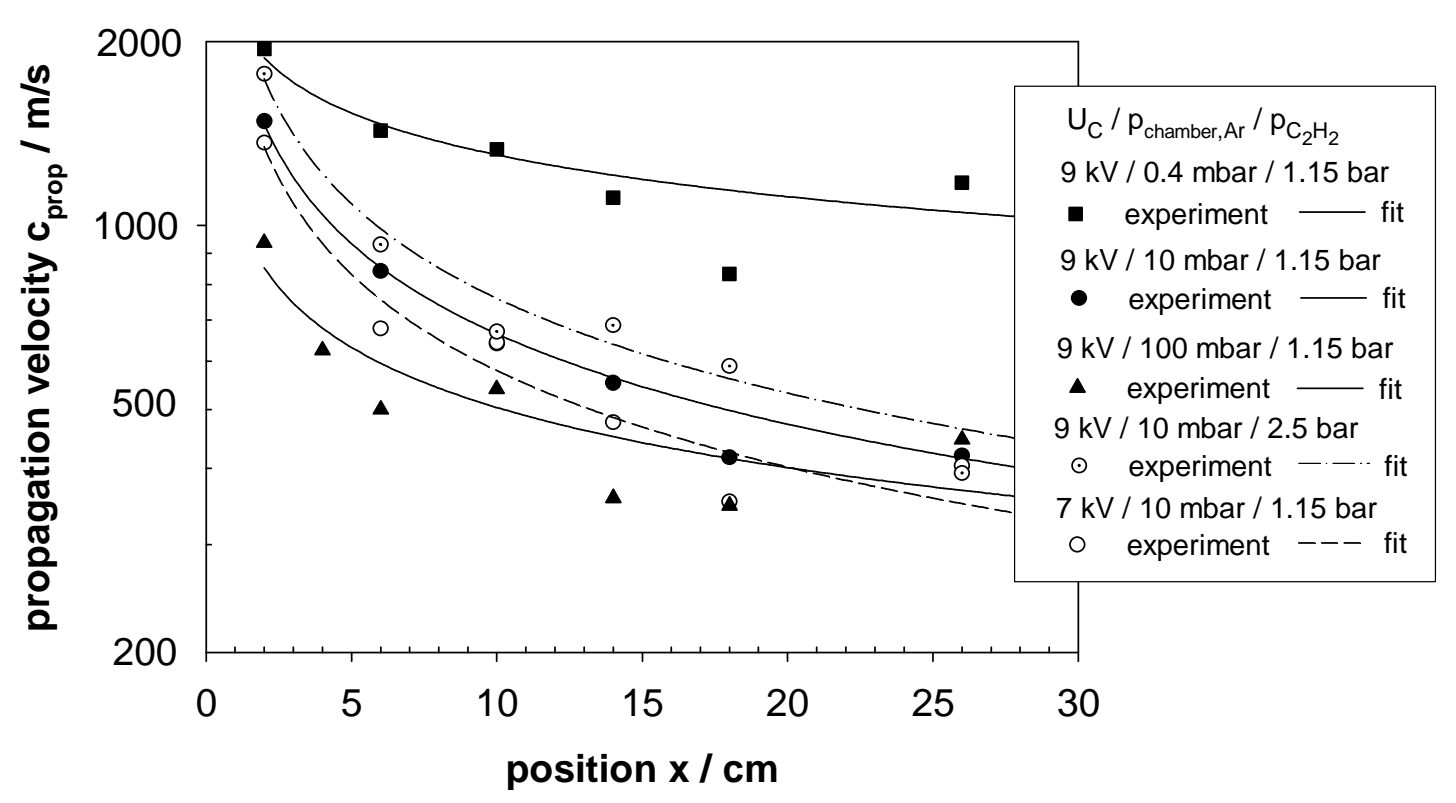

Fig. 5: Axial progression of the propagation velocity $c_{\text {prop }}$ as a function of the process variables $\mathrm{U}_{\mathrm{C}}, \mathrm{p}_{\mathrm{chamber}, \mathrm{Ar}}$, and $\mathrm{p}_{\mathrm{C} 2 \mathrm{H} 2}$.

Short time photography is applied in order to visualise the propagation of the plasma jet. Fig. 6 depicts the side view of an evolving plasma jet, i.e. frames referring to different time delays after initiation of the capacitor discharge. Due to the limitation to single-frame photography, the pictures refer to different experiments made under identical process conditions. The frames displayed in fig. 6 join the views obtained from the first two windows of the expansion chamber located along the propagation axis. The depicted region covers the $15 \mathrm{~cm}$ which are closest to the opening mouth of the discharge chamber. The different delay times referred to in fig. 6 each correspond to the delay between the initiation of the capacitor discharge and the beginning of the exposure, which is set to $10 \mu \mathrm{s}$ for all frames displayed here. The plasma propagates very quickly and already reaches the left hand-side of the second window after $18 \mu \mathrm{s}$ (delay + overall exposure time). The expansion velocity derived thereof is around $1270 \mathrm{~m} / \mathrm{s}$ which is consistent with the results obtained from measuring the propagation of the pressure front (fig. 5). For later process stages, in particular at $415 \mu \mathrm{s}$, the luminescent part of the plasma jet degenerates and its visible front is well behind the pressure wave.

Another series of short time photography (fig. 7) documents the significant dependence of the plasma expansion on the ambient pressure in the expansion chamber. Increasing the argon pressure decelerates the velocity of the plasma jet and additionally leads to a lateral contraction of its front. An argon pressure of 100 mbar delays any significant propagation into the expansion chamber to nearly $60 \mu \mathrm{s}$ after initiation of the arc discharge, so that no significant luminosity is visible at $\mathrm{t}=30 \mu \mathrm{s}$. 


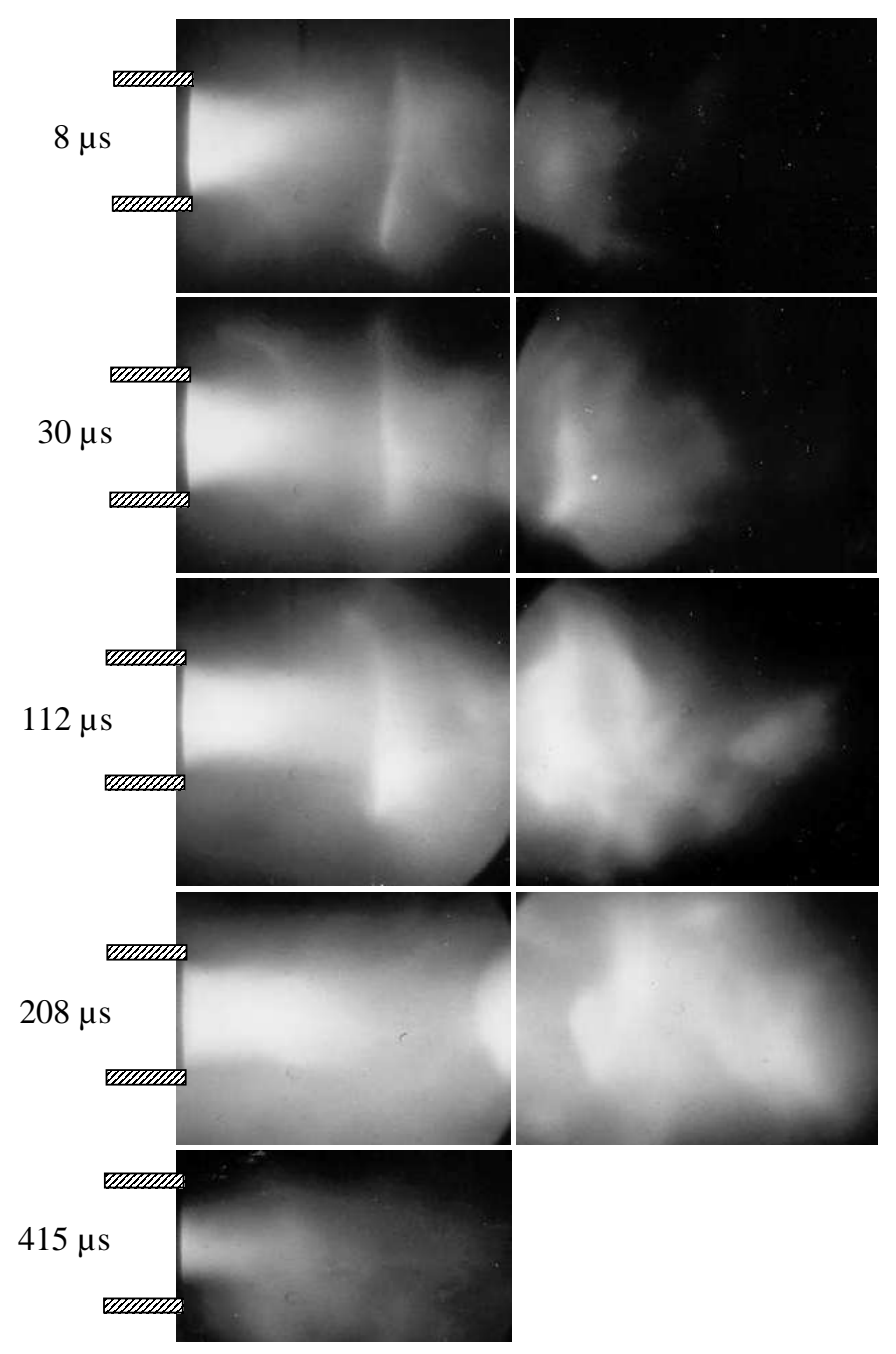

Fig. 6: Short time photographs (side views) of the plasma-jet along the propagation axis $\left(\mathrm{U}_{\mathrm{C}}=\right.$ $9 \mathrm{kV}, \mathrm{p}_{\text {chamber, } \mathrm{Ar}}=10 \mathrm{mbar}, \mathrm{p}_{\mathrm{C} 2 \mathrm{H} 2}=1.15$ bar, and $\left.\mathrm{v}_{\mathrm{C} 2 \mathrm{H} 2}=4.4 \mathrm{~cm}^{3}\right)$.

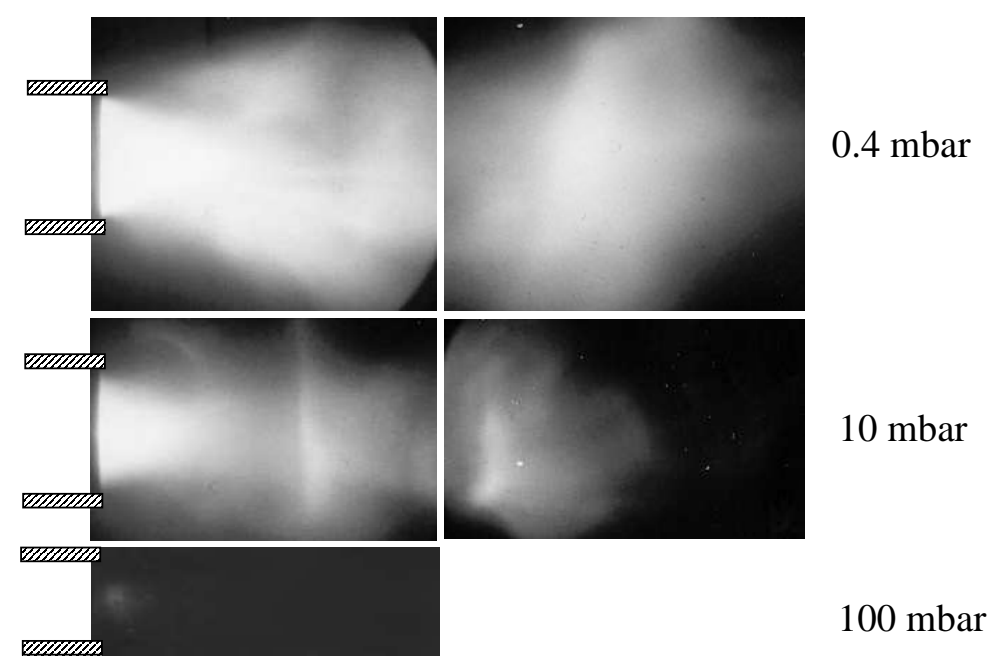

Fig. 7: Short time photographs (side views) of the plasma-jet along the propagation axis at $\mathrm{t}=$ $30 \mu \mathrm{s}$ for different Ar-pressures $\left(\mathrm{U}_{\mathrm{C}}=9 \mathrm{kV}, \mathrm{p}_{\mathrm{C} 2 \mathrm{H} 2}=1.15\right.$ bar, and $\left.\mathrm{v}_{\mathrm{C} 2 \mathrm{H} 2}=4.4 \mathrm{~cm}^{3}\right)$. 


\subsubsection{Temperature and electron density}

The plasma is finally characterised in terms of temperature and electron density. Fig. 8 shows the electron density $\mathrm{n}_{\mathrm{e}}$ and the discharge current $\mathrm{I}$ as a function of time. Since the CCD camera chip needs around $500 \mu \mathrm{s}$ to store the recorded data, it is necessary to repeat experiments under identical process conditions numerous times in order to obtain a detailed temporal resolution ( $\rightarrow$ dotted line). Therefore, data integration is typically carried out for individual half-waves ( $\rightarrow$ circular formed symbols) in order to limit the number of experiments to some practicable extend. The spectroscopic measurements are carried out face-on into the opening of the discharge chamber. Consequently, they do not provide any local resolution. Instead, the recorded signal is dominated by the emission from the discharge chamber and may hence be expected to represent the average values in there reasonably well. The progression of the electron density follows the absolute value of the current pulse with local minima at $\mathrm{I}(\mathrm{t})=0 . \mathrm{n}_{\mathrm{e}}$ increases significantly with the charging voltage: During the first half-wave it amounts to $7.3 \cdot 10^{22} \mathrm{~m}^{-3}$ for $\mathrm{U}_{\mathrm{C}}=5 \mathrm{kV}$ and to $1.3 \cdot 10^{23} \mathrm{~m}^{-3}$ for $\mathrm{U}_{\mathrm{C}}=9 \mathrm{kV}$. The remarkably fast decline of the electron density for $\mathrm{t} \geq 300 \mu \mathrm{s}$ is due to the gradually extinguishing arc discharge (fig. 6). The generation of electrons is about to cease and no longer capable of compensating for the charge degradation due to recombination in the gas phase and at the walls of the apparatus.

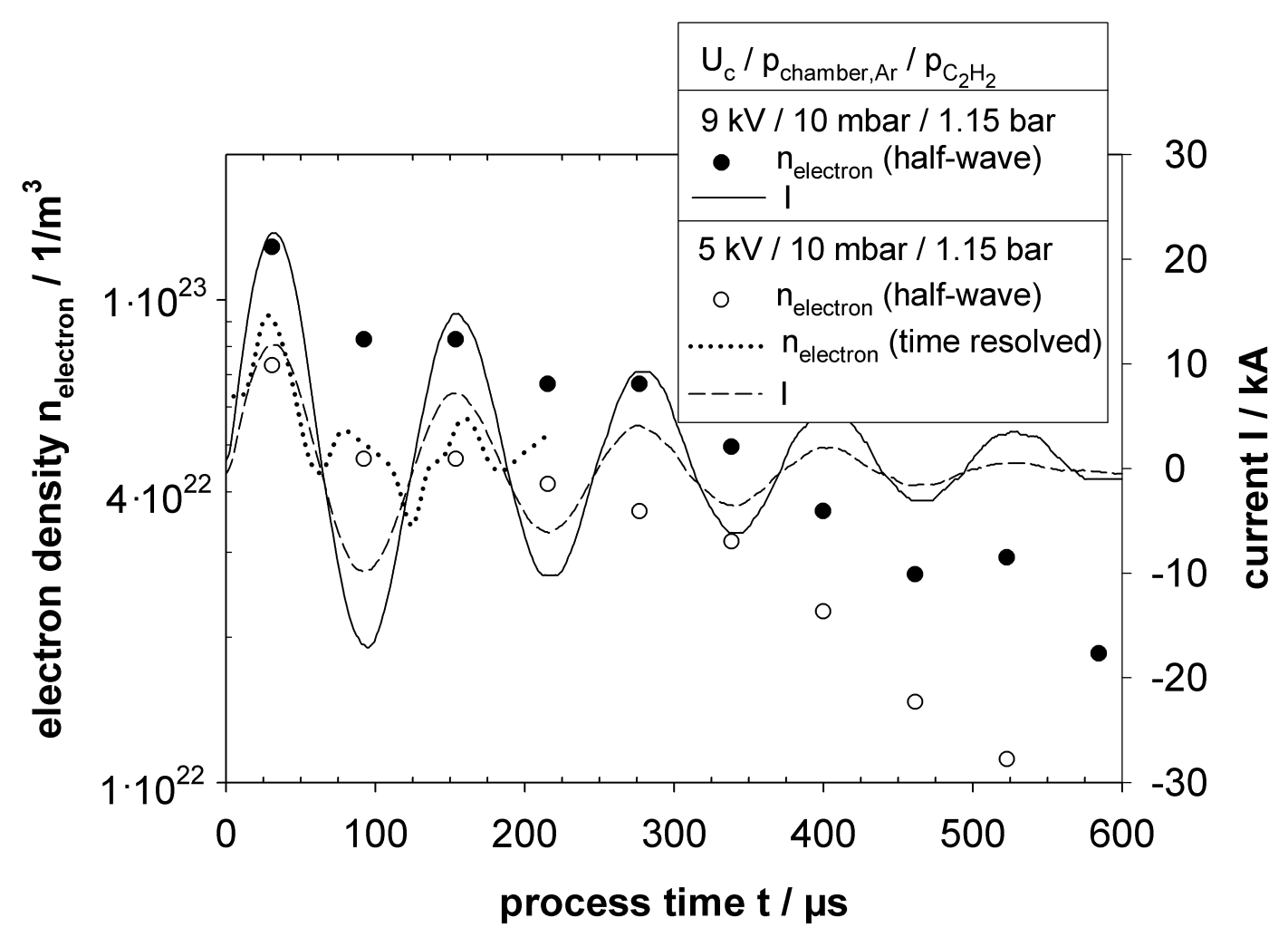

Fig. 8: Progression of the electron density $n_{e}$ and the current $I$ for $U_{C}=5 \mathrm{kV}$ and $9 \mathrm{kV}$, respectively ( $\mathrm{p}_{\text {chamber,Ar }}=10$ mbar and $\mathrm{p}_{\mathrm{C} 2 \mathrm{H} 2}=1.15$ bar $)$.

Spectroscopic measurements also permit to obtain the electron and the gas temperature (fig. 9). In the arc channel itself, $T_{e}$ is derived from evaluating argon and zinc line spectra, as described in section 3.1. During an arc discharge referring to $\mathrm{U}_{\mathrm{C}}=5 \mathrm{kV}, \mathrm{T}_{\mathrm{e}}$ is around 18,000 to $20,000 \mathrm{~K}$ and - this is in contrast to the evolution of the electron density - barely decreases along the discharging process. Measurements carried out at different locations in front of the opening mouth of the discharge chamber show that $T_{e}$ drops to 7,000 $\mathrm{K}$ just a few $\mathrm{mm}$ in front 
of the opening and that it continues to decrease to around $5,500 \mathrm{~K}$ at a distance of $13.5 \mathrm{~cm}$. The profile of $\mathrm{T}_{\mathrm{e}}$ remains quite stable as long as the arc discharge is in progression. The gas temperature $\mathrm{T}_{\text {gas }}$ can be derived from $\mathrm{C}_{2}$-bands: It is around $4,500 \mathrm{~K}$, stable along t, and nearly independent of the spatial position. The sudden ending of the discharge depends on $U_{C}$ (fig.4) and leads to quite an abrupt decrease of the light intensity, so that emission spectroscopy is no longer applicable. Temperature and electron density are therefore not accessible when particle formation and growth actually take place.

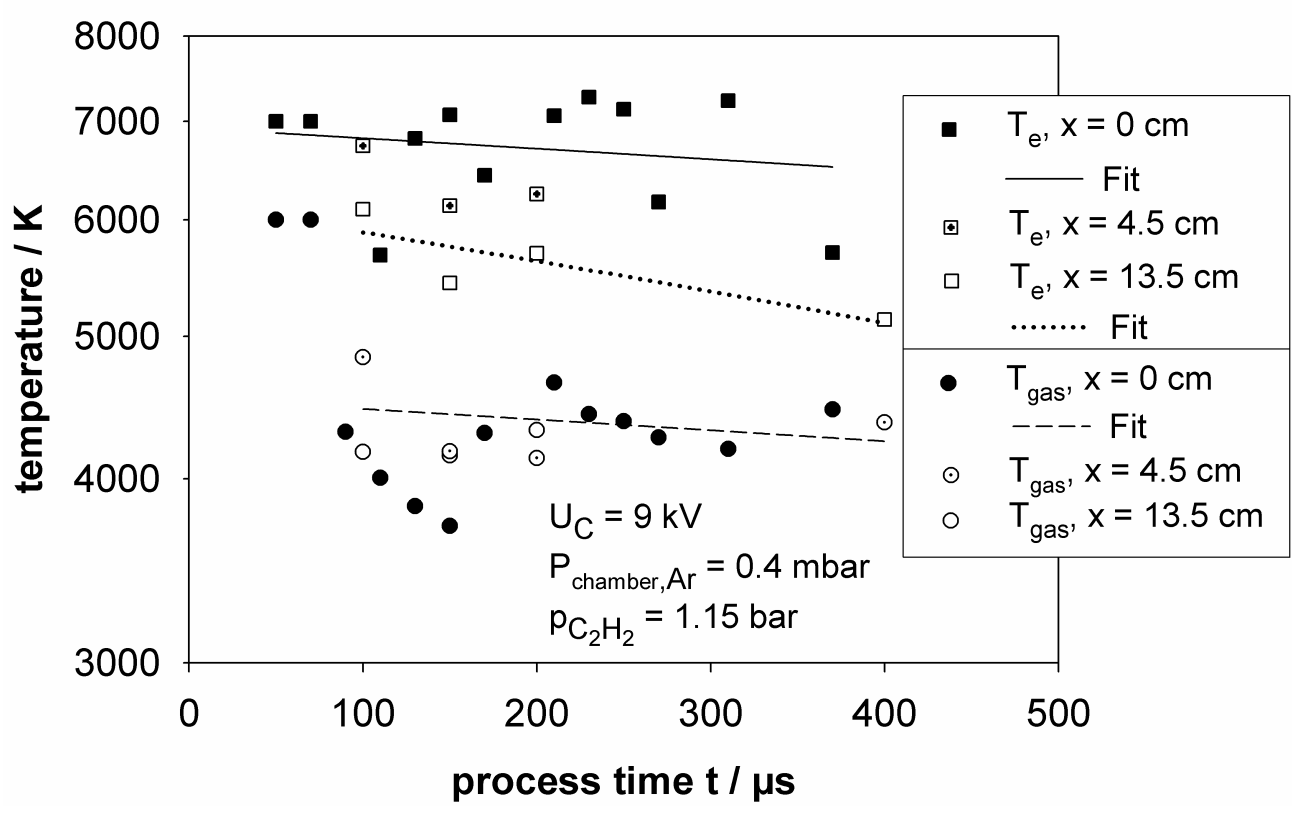

Fig. 9: Electron- and gas temperature for $\mathrm{U}_{\mathrm{C}}=5 \mathrm{kV}$ and $9 \mathrm{kV}$, respectively $\left(\mathrm{p}_{\text {chamber,Ar }}=10\right.$ mbar, and $\mathrm{p}_{\mathrm{C} 2 \mathrm{H} 2}=1.15$ bar

\subsection{Particle properties}

This section aims at investigating correlations between process variables - namely energy coupling, Ar-pressure in the expansion chamber, and injection pressure - and particle properties, i.e. primary particle size, aggregate size, and structure. It is important to note that particle generation and growth are confined to the plasma quench and do actually not take place in the plasma itself, where it is too hot for high supersaturations to occur, such as required to initiate particle formation and growth from the vapour phase [22, 23]. Plasma propagation and particle synthesis therefore happen to be separate events in terms of time and/or space.

\subsubsection{Energy Coupling}

SEM-micrographs of product particles identified as carbon black by means of carrying out EDX-analysis are shown in fig. 10. The micrographs refer to different initial charging voltages of the capacitor bank, i.e. to different levels of energy coupling (fig. 4c). For all capacitor voltages applied small individual spherical particles as well as openly structured $\mu \mathrm{m}$ sized aggregates are obtained in parallel. The size of the primary particles and of the individual spheres is around 30 to $35 \mathrm{~nm}$ and nearly independent from the capacitor voltage applied (for $\mathrm{p}_{\text {chamber,Ar }}=10$ mbar and $\mathrm{p}_{\mathrm{C} 2 \mathrm{H} 2}=1.15$ bar). This must be due to similar particle 
formation and early growth conditions, i.e. similar conditions in terms of temperature, saturation and charging history.

This is certainly quite true for the temperature history in spite of the strong dependence of the plasma temperature on $\mathrm{U}_{\mathrm{C}}$ [16]: The pressure along the propagation axis in the expansion chamber is clearly sub-atmospheric. Radiation therefore turns out to be the dominant mechanism for heat transfer, so that $\mathrm{T}(\mathrm{t})$ (mostly) depends on the momentary temperature and on the material of the particles and the walls of the instrumentation [24]. The different profiles therefore turn out to be nearly identical when particle formation and growth actually take place. Increasing $\mathrm{U}_{\mathrm{C}}$ leads to a higher density of individual spherical and aggregate particles on the surface of the collecting targets. However, increasing the initial capacitor voltage has two nearly outbalancing effects on particle formation and growth: on the one hand the overall amount of precursor dissociated increases, on the other hand the volume where $\mathrm{T}$ is sufficiently high for that dissociation may take place is also larger. As a consequence, the supersaturation profile and thus nucleation rates and local amount of precursor available for surface reaction [25] are probably only little affected. The primary particles depicted in the micrographs of fig. 10 are all quite large in size, i.e. around $30 \mathrm{~nm}$, such as frequently observed in flame reactors [20] but also in (quasi) stationary plasmas [21]. Provided that the particle concentration and residence time in the quench of the pulsed plasma jet are sufficiently high for that coagulation and sintering may - besides surface reaction potentially play an important role for primary particle growth one may tend to conclude that free charges, although initially present at concentrations of the order of $10^{23} \mathrm{~m}^{-3}$ and more, do not significantly suppress collision rates and hence growth of freshly generated (primary) particles. This conclusion is in agreement numerical investigations such as of Hoppel and Frick [26] who where able to show that nanoscaled particles smaller than around 20 to $30 \mathrm{~nm}$ mostly remain uncharged, even in the presence of an initially high excess of free charges. The round primary particle shape observed may therefore not only be a result of surface growth, but - provided that the mobility and the collision rates of the nm-sized particles are sufficiently high - also be due to collision and rapid subsequent sintering.

The aggregates observed for all capacitor voltages applied result from coagulation and partial sintering further away from the reaction zone where the temperature has cooled down and sintering has become rather slow. As the primary particle and later on the aggregate size continue to grow, the likelihood for charging, which results from collisions between particles and free electrons or ions (positively as well as negatively charged),continues to increase [26]. Although the plasma is a globally bipolar system one may yet expect a large majority of particles being negatively charged. This is due to the high mobility of the free electrons. As a result, agglomeration is largely suppressed allowing for many individual spherical particles to continue existing. However, some particles will also become positively charged. Attractive forces between oppositely charged particles will favour their collision [27] and lead to the formation of openly structured aggregates [28] such as also observed here.

\subsubsection{Counter- and injection pressure}

Altering the counter-pressure in the expansion chamber (i.e. $\mathrm{p}_{\text {chamber,Ar}}$ ) has - in contradiction to varying the energy coupling - a strong impact on primary particle size (fig. 11): Low pressures do not decelerate the plasma jet remarkably. Higher counter-pressures, however, lead to a drastic reduction of its propagation velocity (fig. 5) and to lateral contraction of the jet (fig. 7). As a consequence one may expect elevated local precursor concentrations and longer residence times within the temperature region relevant for particle formation. This favours surface growth, but also coagulation and sintering [29]. At $\mathrm{p}_{\text {chamber,Ar }}=100 \mathrm{mbar}$, this 
leads to enhanced primary particle growth and to the formation of compact aggregates, which do not contain more than a few primary particles with diameters of around $70 \mathrm{~nm}$.

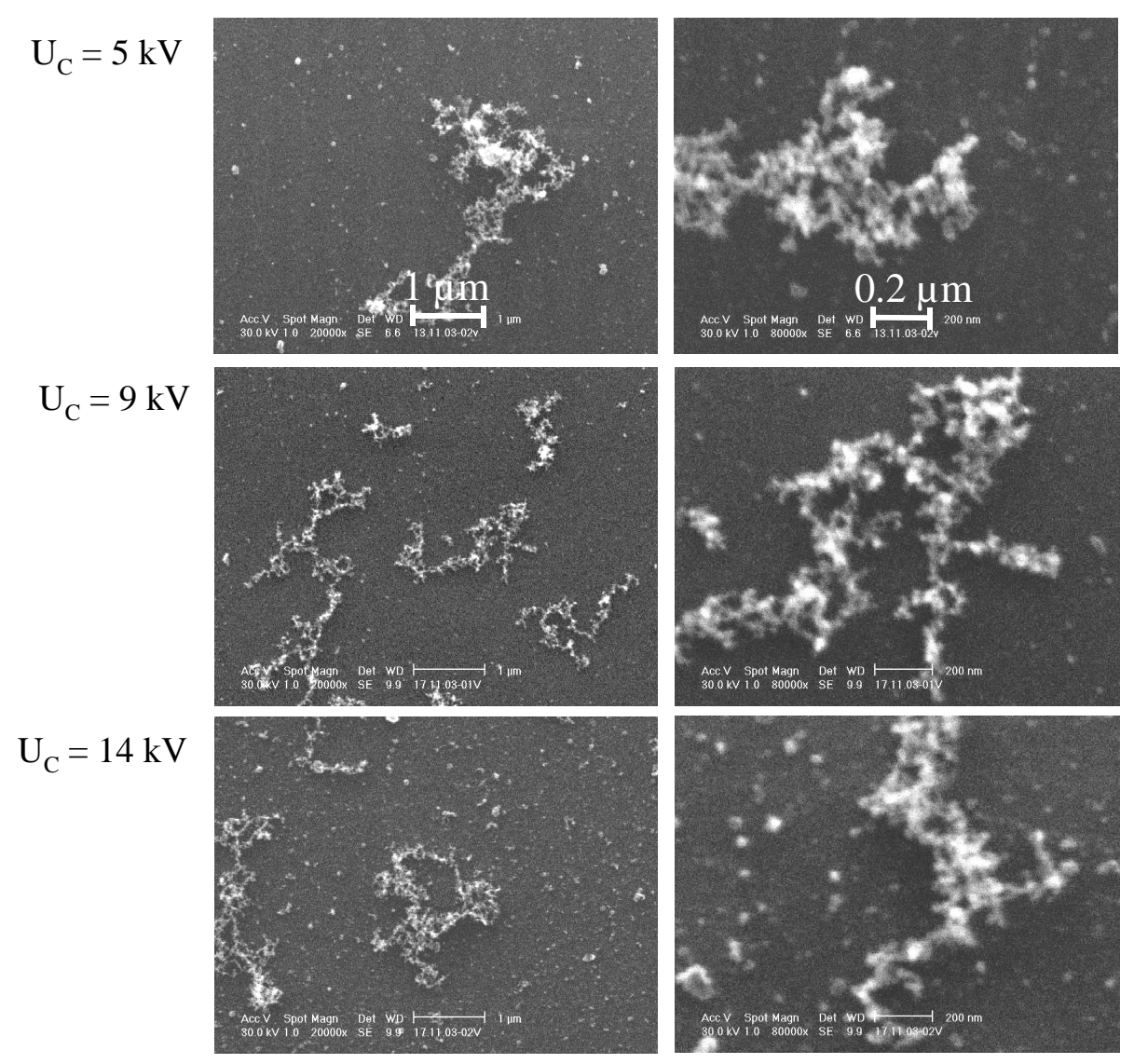

Fig. 10: SEM-micrograps of product particles obtained at $\mathrm{p}_{\text {chamber, } \mathrm{Ar}}=10 \mathrm{mbar}, \mathrm{p}_{\mathrm{C} 2 \mathrm{H} 2}=1.15$ bar and varying capacitor voltage $\mathrm{U}_{\mathrm{C}}$.

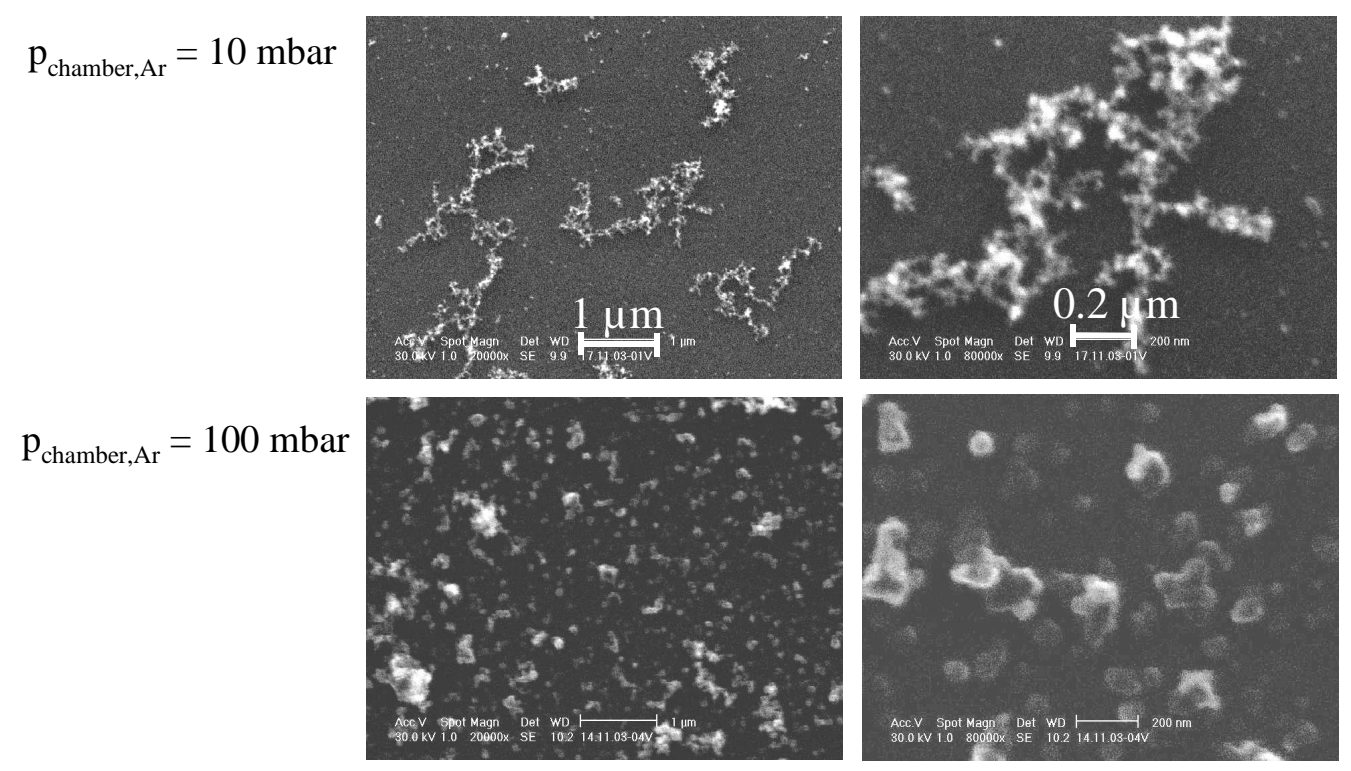

Fig. 11: SEM-micrograps of product particles obtained at $\mathrm{U}_{\mathrm{C}}=9 \mathrm{kV}, \mathrm{p}_{\mathrm{C} 2 \mathrm{H} 2}=1.15$ bar, and a counterpressure $p_{\text {chamber,Ar }}$ of 10 and 100 mbar, respectively. 
Similar as with $\mathrm{p}_{\text {chamber,Ar, }}$, raising the $\mathrm{C}_{2} \mathrm{H}_{2}$ injection-pressure also leads to elevated local precursor concentrations. However, the higher propagation velocity involved (fig. 5) is responsible for somewhat shorter residence times. The increase of the primary particle growth rate is therefore less pronounced, and primary particles with diameters of the order of $50 \mathrm{~nm}$ are obtained (for $\mathrm{U}_{\mathrm{C}}=9 \mathrm{kV}$, $\mathrm{p}_{\text {chamber, } \mathrm{Ar}}=10 \mathrm{mbar}$, and $\mathrm{p}_{\mathrm{C} 2 \mathrm{H} 2}=2.5 \mathrm{bar}$ ).

\section{Conclusions and Outlook}

A new pulsed coaxial plasma generator (PCPG) was designed, built and put into operation. It allows for synthesising particles under highly transient process conditions. The PCPG was used to investigate the potential of making use of particle-particle interactions to tailor particle characteristics for the case of carbon black manufacture. The highly transient pulsed plasma process is characterised by initially steep temperature gradients and by high charge densities which can be significantly varied by means of altering process parameters, such as the energy coupling.

Product-, i.e. carbon black properties, such as primary particle size, are shown to be nearly independent from the energy coupling which suggests that the temperature profile and the charging history within the particle forming regime do either not significantly depend on the initial plasma conditions or that they are of minor importance for the formation and growth process: radiation is the dominant mechanism for heat transfer and therefore probably leads to similar temperature evolutions regardless the initial condition. On the other hand, charging does not seem to influence growth of particles smaller than around $30 \mathrm{~nm}$. This may be either because growth is entirely dominated by surface reaction or because particle charging is - in spite of the initially high charge densities of more than $10^{23} \mathrm{~m}^{-3}$ and the steep temperature gradients - insufficient to alter the coagulation behaviour.

The synthesis of extremely fine particles with primary particles no larger than a few nm [30] and little degree of aggregation can apparently not be realised by making use of the highly transient process conditions as typical for the pulsed coaxial plasma generator. At later process stages, i.e. once particles have significantly grown, charging may well occur and be decisive upon structure formation, such as of single spherical particles and of openly structured aggregates [28].

\section{Acknowledgements}

The authors gratefully acknowledge financial support obtained from the German Research Foundation (DFG) (Project No. PE 427/8-1).

\section{References}

[1] B.A. Kalin, V.L. Yakushin, V.L. Vasiliev, S.S. Tserevitinov. Use of high temperature pulsed plasma fluxes in modification of metal materials. Surface and Coatings Techn., 96, 110 - 116 (1997).

[2] J. Piekoszewski, Z. Werner, W. Szymczyk. Application of high intensity pulsed ion and plasma beams in modification of materials. Vacuum, 63, 475 - 481 (2001).

[3] M.J. Sadowski, J. Baranowski, E. Skladnik-Sadowska, V.N. Borisko, O.V. Byrka, V.I. Tereshin, A.V. Tsarenko. Characterization of pulsed plasma-ion streams emitted from RPItype devices applied for material engineering. Applied Surface Sci., 238, 433 - 437 (2004). 
[4] M. Rott, C. Artelt, T. Höschen. Experimental Investigation of Hypervelocity Plama Jets Generated with a Coaxial Arc Device. IEEE Transactions on Magnetics, 41 (1), 220 - 225 (2005).

[5] P. Yan, P. Hui, W. Zhu, H. Tan. An investigation of the pulsed plasma for deposition of thin film materials. Surface and Coatings Technology, 102, 175 - 181 (1998).

[6] R.L. Ellis, J.C. Poynor, B.T. McGlasson, A.N. Smith. Influence of bore and rail geometry on an electromagnetic naval railgun system. IEEE Transactions on Magnetics 41(1), 182 187 (2005).

[7] I.R. McNab, F. Stefani, M. Crawford, M. Erengil, C. Persad, H. Satapathy, H. Vanicek, T. Watt, C. Dampier. Development of a naval railgun. IEEE Transactions on Magnetics, 41(1), $206-210(2005)$.

[8] E. Igenbergs, S. Aigner, A. Hüdepohl, M. Rott, U. Weishaupt, H. Kuczera. The TUM/LRT Electromagnetic Launchers. IEEE Transactions on Magnetics, 22(6), 1536 - 1540 (1986).

[9] M. Rott. Design Optimizations of a Small Caliber Electrothermal Accelerator. IEEE Transactions on Magnetics, 31 (1), 441 - 446 (1995).

[10] S.D. Barson, P. Skeldon, G.E. Thompson, J. Piekoszewski, A.G. Chmielewski, Z. Werner, R. Grötzschel, E. Wieser. Corrosion protection of titanium by pulsed plasma deposition of palladium. Corrosion Sci., 42, 1213 - 1234 (2000).

[11] Z. Peng, H. Miao, W. Wang, S. Yang, C. Liu, L. Qi. Hard and wear resistant titanium nitride films for ceramic cutting tools by pulsed high energy density plasma. Surface and Coatings Techn., 166, 183 - 188 (2003).

[12] H. Miao, F. Shi, Z. Peng, S. Yang, C. Liu, L. Qi. Nanometer grain titanium carbonitride coatings with continuously graded interface onto silicon nitride cutting tools by pulsed high energy density plasma. Materials Sci. and Engineering A, 284, 202 - 208 (2004).

[13] M. Voll, P. Kleinschmit. Carbon Black. In Ullmann's Encyclopedia of Industrial Chemistry, $5^{\text {th }}$ edition, Vol. A5, $140-158$, VCH, Weinheim (1986).

[14] H.R. Griem. Spectral lines broadening by plasmas. Academic Press, New York (1974).

[15] V. Helbig, K.-P. Nick. Investigation of the Stark broadening of Balmer beta. J. Phys. B, 14, 3573 - 3583 (1981).

[16] A. Eichhorn, H. Mach, D. Rösch. Optische und spektroskopische Untersuchungen an einem Plasmabrenner mit evakuierbarer Messkammer und Ermittlung der Plasmatemperatur mit Hilfe von Kupferlinien. Deutsch-Französisches Forschungsinstitut Saint-Louis, Bericht R 124/98 (1998).

[17] K. Behringer. Diagnostics and modelling of ECRH microwave discharges. Plasma Phys. Contr. Fusion, 33, 997 - 1028 (1991).

[18] C.V.V. Prasad, P.F. Bernath. Fourier transform spectroscopy of the Swan $\left(\mathrm{d}^{3} \Pi_{\mathrm{g}}-\mathrm{a}{ }^{3} \Pi_{\mathrm{u}}\right)$ system of the jet-cooled $\mathrm{C}_{2}$ molecule, Astrophys. J., 426, 812 - 821 (1994).

[19] H.K. Kammler, R. Jossen, P.W. Morrison, S.E. Pratsinis, G. Beaucage. The effect of external electric fields during flame synthesis of titania. Powder Techn., 135 - 136, 310 - 320 (2003).

[20] P. Roth, A.V. Filippov. In situ ultrafine particle sizing by a combination of pulsed laser heatup and particle thermal emission. J. Aerosol Sci., 27, 95 - 104 (1996). 
[21] R. Sommer, S. Dankers, A. Leipertz. Prozesskontrolle bei der Synthese nanoskaliger Partikel. Chemie Ingenieur Technik , 77, 214 - 273 (2005).

[22] C. Artelt, H.-J. Schmid, W. Peukert. On the impact of accessible surface and surface energy on particle formation and growth from the vapour phase. J. Aerosol Sci., 36, 147 - 172 (2005).

[23] C. Artelt, H.-J. Schmid, W. Peukert. Modelling titania formation at typical industrial process conditions: effect of structure and material properties on relevant growth mechanisms. Chem. Eng. Sci., 61, 18 - 32 (2006).

[24] E.-U. Schlünder, E. Tsotsas. Wärmeübertragung. Georg Thieme Verlag, Stuttgart (1988).

[25] M. Frenklach. On surface growth mechanisms of soot particles. $26^{\text {th }}$ Symposium (International) on Combustion / The Combustion Institute, 2285 - 2293 (1996).

[26] W.A. Hoppel, G.M. Frick. Ion - aerosol attachment coefficients and the steady-state charge distribution on aerosols in a bipolar ion environment. Aerosol Sci. Techn., 5, 1 - 21 (1986).

[27] T. Matsoukas. The coagulation rate of charged aerosols in ionized gases. J. Colloid Interface Sci., 187, 474 - 483 (1997).

[28] A. Gutsch, F. Löffler. Electrically enhanced agglomeration of nanosized aerosols. J. Aerosol Sci., 25, suppl. 1, S307 - S308 (1994)

[29] C. Artelt, H.-J. Schmid, W. Peukert. On the relevance of accounting for the evolution of the fractal dimension in aerosol process simulations. J. Aerosol Sci., 34, 511 - 534 (2003).

[30] D. Lindackers, P. Roth. Erzeugung und Charakterisierung von oxidkeramischen Partikeln in einem Niederdruck-Flammenreaktor - Teil 2: Synthese von $\mathrm{SiO}_{2}$-Partikeln. Chemie Ingenieur Technik, 69, 143 - 146 (1997). 